J. Pestic. Sci., 31(2), 110-115 (2006)

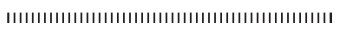

Original Article

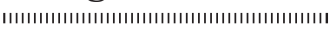

\title{
Quantitative structure-activity relationships of imidacloprid and its analogs with substituents at the $C 5$ position on the pyridine ring in the neuroblocking activity
}

\author{
Keiichiro Nishimura, Kazuhisa KIRIYAMA and Shinzo KagabU ${ }^{\dagger}, *$ \\ Research Institute for Advanced Science and Technology, Osaka Prefecture University, Osaka 599-8570, Japan \\ ${ }^{\dagger}$ Department of Chemistry, Faculty of Education, Gifu University, Gifu 501-1193, Japan
}

(Received October 11, 2005; Accepted December 12, 2005)

\begin{abstract}
Two nerve activities of imidacloprid analogs with various substituents at the 5-position of the pyridine ring were measured: the conduction blockage in the excised central nerve cord of the American cockroach, and the binding inhibition of a radioligand, $\left[{ }^{3} \mathrm{H}\right]$ imidacloprid, to the membrane preparation of housefly-head homogenates. Neuroblocking activity was quantitatively analyzed using physicochemical substituent parameters. The greater the electron-releasing resonance effect, the higher the activity. The introduction of sizable and alkoxy substituents was unfavorable. The nerve-binding activity of the tested compounds was linearly related to the neuroblocking activity with one exception. The higher the binding activity, the higher the blocking activity. C Pesticide Science Society of Japan
\end{abstract}

Keywords: imidacloprid analogs, QSAR, neuroblocking activity, radioligand, $\left[{ }^{3} \mathrm{H}\right]$ imidacloprid.

\section{Introduction}

Imidacloprid (1, $\mathrm{X}=\mathrm{H}$ in Fig. 1) began the era of a structurally as well as a physiologically new type of insecticides having highly effective and widely used chemicals for crop protection and veterinary pest control. ${ }^{1)}$ Starting from this compound, variously modified neonicotinoids were developed as highly effective insecticides. ${ }^{2}$ Early modification researches focused overwhelmingly on the imidazolidine moiety of imidacloprid and cyclic and acyclic isosters were contrived. Recently, a non-aromatic neonicotinoids bearing a saturated heterocyclic ring in place of the pyridine ring, dinotefuran, was developed. ${ }^{3,4)}$

For further evolution of the structure to give a new class of neonicotinoids, quantitative analyses of the structure-activity

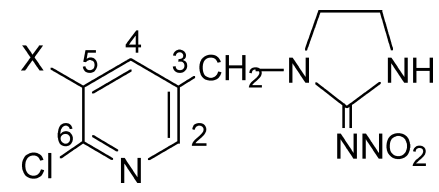

Fig. 1. 5-X substituted imidacloprid derivatives.

\footnotetext{
* To whom correspondence should be addressed. E-mail: kagabus@cc.gifu-u.ac.jp

(C) Pesticide Science Society of Japan
}

relationship of neonicotinoids and analogous compounds are one of the most important tools, and have been widely performed for this class of compounds by means of conformational, $^{5)}$ three-dimensional $^{6-8)}$ as well as substituent-effect analyses. ${ }^{9,10)}$ The conformational analysis, however, was conducted only for limited structures related to dinotefuran, so that the results obtained cannot be generalized. The other analyses were mostly carried out for the imidazolidine moiety of imidacloprid and the corresponding parts of the series compounds. Although a number of variously substituted benzyl analogs of imidacloprid were prepared, ${ }^{11)}$ their substituent effects have not been quantitatively analyzed.

To conduct more detail quantitative analysis of the aromatic-ring part, we prepared a set of compounds with various substituents at the 5-position on the pyridine ring of imidacloprid and measured their insecticidal activity. ${ }^{12,13)}$ Here, we report their substituent effects obtained by means of the quantitative analysis of neuroblocking activity. This work is also connected with a recent finding of the extraordinary binding affinity of 5-azidoimidacloprid (21, $\mathrm{X}=\mathrm{N}_{3}$, Fig. 1) to insect nAChR. ${ }^{14,15)}$ We will be able to view the new information about the azido group in light of the quantitative analysis of a set of substituents at this position. 
Table 1. Neuroblocking activity of test compounds and physicochemical parameters for their substituents ${ }^{a)}$

\begin{tabular}{|c|c|c|c|c|c|c|c|c|}
\hline \multirow{2}{*}{ No. } & \multirow{2}{*}{$\mathrm{X}$} & \multicolumn{2}{|c|}{$\log (1 / \mathrm{BC})(\mathrm{M})$} & \multirow{2}{*}{$\pi$} & \multirow{2}{*}{$\Delta B_{5}$} & \multirow{2}{*}{$F$} & \multirow{2}{*}{$R$} & \multirow{2}{*}{$I_{\mathrm{OR}}$} \\
\hline & & Obs. $^{b)}$ & Calcd. $^{c)}$ & & & & & \\
\hline 1 & $\mathrm{H}$ & $5.70(5.63-5.78)$ & 5.37 & $0.00^{d)}$ & 0.00 & 0.00 & 0.00 & 0.00 \\
\hline 2 & $\mathrm{~F}$ & $5.99(5.86-6.10)$ & 6.13 & 0.19 & 0.35 & 0.45 & -0.39 & 0.00 \\
\hline 3 & $\mathrm{Cl}$ & $5.61(5.51-5.72)$ & 5.42 & 0.42 & 0.80 & 0.42 & -0.19 & 0.00 \\
\hline 4 & $\mathrm{Br}$ & $5.51(5.45-5.58)$ & 5.41 & 0.53 & 0.95 & 0.45 & -0.22 & 0.00 \\
\hline 5 & I & $5.30(5.17-5.42)$ & 5.36 & 0.65 & 1.15 & 0.42 & -0.24 & 0.00 \\
\hline 6 & $\mathrm{CH}_{3} \mathrm{O}$ & $4.98(4.88-5.12)$ & 4.98 & -0.18 & 2.07 & 0.29 & -0.56 & 1.00 \\
\hline 7 & $\mathrm{C}_{2} \mathrm{H}_{5} \mathrm{O}$ & $4.66(4.62-4.70)$ & 4.69 & 0.03 & 2.36 & 0.26 & -0.50 & 1.00 \\
\hline 8 & $n-\mathrm{C}_{3} \mathrm{H}_{7} \mathrm{O}$ & $4.56(4.52-4.60)$ & 4.17 & 0.12 & 3.42 & 0.26 & -0.51 & 1.00 \\
\hline 9 & $i-\mathrm{C}_{3} \mathrm{H}_{7} \mathrm{O}$ & $4.46(4.43-4.50)$ & 5.01 & 0.17 & 3.10 & 0.34 & -0.79 & 1.00 \\
\hline 10 & $n-\mathrm{C}_{4} \mathrm{H}_{9} \mathrm{O}$ & $4.58(4.54-4.62)$ & 4.23 & 0.37 & 3.79 & 0.29 & -0.61 & 1.00 \\
\hline 11 & $n-\mathrm{C}_{5} \mathrm{H}_{11} \mathrm{O}$ & $3.59(3.57-3.62)$ & 3.75 & 0.43 & 4.81 & 0.29 & -0.63 & 1.00 \\
\hline 12 & $\mathrm{CH}_{3}$ & $5.25(5.19-5.32)$ & 5.27 & 0.32 & 1.04 & 0.01 & -0.18 & 0.00 \\
\hline 13 & $\mathrm{C}_{2} \mathrm{H}_{5}$ & $4.66(4.65-4.67)$ & 4.62 & 0.57 & 2.17 & 0.00 & -0.15 & 0.00 \\
\hline 14 & $n-\mathrm{C}_{3} \mathrm{H}_{7}$ & $4.51(4.46-4.56)$ & 4.43 & 0.69 & 2.49 & 0.01 & -0.14 & 0.00 \\
\hline 15 & $n-\mathrm{C}_{4} \mathrm{H}_{9}$ & $3.79(3.71-3.84)$ & 3.92 & 0.81 & 3.54 & -0.01 & -0.15 & 0.00 \\
\hline 16 & $\mathrm{C}_{6} \mathrm{H}_{5}$ & $4.46(4.44-4.48)$ & 4.60 & 0.51 & 2.11 & 0.12 & -0.13 & 0.00 \\
\hline 17 & $\mathrm{CF}_{3}$ & $4.43(4.40-4.49)$ & 4.16 & -0.07 & 1.61 & 0.38 & 0.16 & 0.00 \\
\hline 18 & $\mathrm{COOCH}_{3}$ & $3.92(3.84-3.97)$ & 3.90 & -0.28 & 2.36 & 0.34 & 0.11 & 0.00 \\
\hline 19 & $\mathrm{CN}$ & $4.59(4.53-4.65)$ & 4.70 & -0.29 & 0.60 & 0.51 & 0.15 & 0.00 \\
\hline 20 & $\mathrm{NO}_{2}$ & $3.60(3.55-3.65)$ & 4.32 & -0.02 & 1.44 & 0.65 & 0.13 & 0.00 \\
\hline 21 & $\mathrm{~N}_{3}$ & $4.98(4.93-5.03)$ & 4.71 & -0.09 & 3.18 & 0.48 & -0.40 & 0.00 \\
\hline
\end{tabular}

${ }^{a)}$ See Fig. 1 for the general structure.

${ }^{b)}$ Values in parentheses show the deviation range estimated from a dose-response relationship.

c) From Eq. (3).

${ }^{d)} \log \mathrm{P}$ for compound 1 was 0.60 .

\section{Materials and Methods}

\section{Chemicals}

$\left[{ }^{3} \mathrm{H}\right]$ Imidacloprid $\left(\left[{ }^{3} \mathrm{H}\right] \mathrm{IMI} ; 1.11 \mathrm{TBq} / \mathrm{mmol}\right)$ was purchased from Amersham Pharmacia Biotech (Buckinghamshire, UK). Test compounds are listed in Table 1. Compounds 1-5 and 19-21 were prepared previously. ${ }^{12)}$ Compounds 6-11 were the same samples as those described previously. ${ }^{13)}$ Preparations of compounds 12, 17 and 18 were described separately. ${ }^{16)}$ Preparation of compounds 13-16 will be described elsewhere.

\section{Neurophysiological test}

The neurophysiological activity of the test compounds was measured practically in the same way as that previously reported. ${ }^{17-19)}$ In brief, the abdominal central nerve cord of an adult male American cockroach, Periplaneta Americana (L), was excised between the fourth and fifth ganglia. A nerve preparation containing the fifth and sixth ganglia was placed in a chamber containing the saline solution ( $\mathrm{pH}$ 7.3). One of two bundles divided from the thoracic side of the nerve cord was tightly taken up with saline into a glass tube, in which a chlorinated silver wire was set as the electrode. As a reference electrode, another silver wire was set outside the tube in the chamber. Spontaneous discharges larger than $15 \mu \mathrm{V}$ were counted with a pulse counter (MET-1100, Nihon Kohden, Tokyo, Japan) over 30-sec periods. Just after setting, the frequency was usually quite high for a few minutes. When the frequency decreased and stabilized within a range of 30-500 counts per $30 \mathrm{sec}$ for $2 \mathrm{~min}$ or more, the saline solution was exchanged for saline containing each test compound dissolved in dimethyl sulfoxide (DMSO) containing an amount of methanol. The final concentration of the organic solvents was lower than $1.5 \%(\mathrm{v} / \mathrm{v})$, which did not affect the neural activity of the compounds. The concentrations of each compound required for the blocking, $\mathrm{BC}(\mathrm{M})$, which will be defined below, were measured at $24-26^{\circ} \mathrm{C}$. Neuroblocking activity values in terms of $\log (1 / \mathrm{BC})$ are listed in Table 1 along with their deviation ranges. The values are listed in Table 2. 
Table 2. Binding activity of test compounds

\begin{tabular}{rll}
\hline No. & \multicolumn{1}{c}{$\mathrm{X}$} & $\log \left(1 / \mathrm{IC}_{50}\right)(\mathrm{M})^{a)}$ \\
\hline $\mathbf{1}$ & $\mathrm{H}$ & $7.70( \pm 0.14)$ \\
$\mathbf{2}$ & $\mathrm{F}$ & $7.48( \pm 0.03)$ \\
$\mathbf{3}$ & $\mathrm{Cl}$ & $6.99( \pm 0.03)$ \\
$\mathbf{4}$ & $\mathrm{Br}$ & $6.82( \pm 0.17)$ \\
$\mathbf{5}$ & $\mathrm{I}$ & $6.47( \pm 0.09)$ \\
$\mathbf{6}$ & $\mathrm{CH}_{3} \mathrm{O}$ & $6.12( \pm 0.21)$ \\
$\mathbf{1 2}$ & $\mathrm{CH}_{3}$ & $6.50( \pm 0.03)$ \\
$\mathbf{1 6}$ & $\mathrm{C}_{6} \mathrm{H}_{5}$ & $5.19( \pm 0.03)$ \\
$\mathbf{1 9}$ & $\mathrm{CN}$ & $6.07( \pm 0.16)$ \\
$\mathbf{2 0}$ & $\mathrm{NO}_{2}$ & $6.59( \pm 0.02)$ \\
\hline
\end{tabular}

${ }^{a)}$ The values in parentheses show the standard deviation from two experimental runs.

\section{3 H]IMI binding to housefly-head membrane fraction}

The membrane fraction was prepared from the heads of both sexes of adult houseflies, Musca domestica (L), according to the reported procedure. ${ }^{711,20)}$ The binding assay was conducted according to the procedure reported previously. ${ }^{20-22)}$ The membrane fraction ( $3 \mathrm{mg}$ protein $/ \mathrm{ml}, 200 \mu \mathrm{l}$ ) was placed in a disposable glass tube $(12 \times 75 \mathrm{~mm})$ containing the test compound dissolved in DMSO $(2 \mu \mathrm{l})$. After incubation at $24^{\circ} \mathrm{C}$ for at least $\left.10 \mathrm{~min},{ }^{3} \mathrm{H}\right] \mathrm{IMI}(50 \mu \mathrm{l})$, which was prepared by dilution with sodium phosphate buffer $(10 \mathrm{mM})$ containing sodium chloride $(50 \mathrm{mM})$ and Triton-X ( $1 \mathrm{~g} /$ liter $), \mathrm{pH} 7.4$, was added so as to make a final concentration of $\left[{ }^{3} \mathrm{H}\right] \mathrm{IMI} 10 \mathrm{nM}$, and the mixture was incubated at $24^{\circ} \mathrm{C}$ for $60 \mathrm{~min}$. The reaction was terminated by rapid filtration through a Unifilter GF/B, which had been treated with a washing buffer consisting of $10 \mathrm{mM}$ sodium phosphate buffer, $\mathrm{pH} 7.4$, and $50 \mathrm{mM}$ sodium chloride. The tube was rinsed with the washing buffer ( $1 \mathrm{ml} \times 2$ times) and filtered immediately. The filter was then washed with the washing buffer $(2.5 \mathrm{ml} \times 4$ times $)$ and dried under an infrared lamp for about $30 \mathrm{~min}$. The radioactivity collected on the filter was measured in Aquasol-2 $(3 \mathrm{ml}$; Packard Instrument Co. Meriden, CT, USA) with an Aloka LSC-1000 counter (Aloka Co. Ltd., Tokyo, Japan). The molar concentrations required for $50 \%$ inhibition of the specific binding of $\left[{ }^{3} \mathrm{H}\right] \mathrm{IMI}, \mathrm{IC}_{50}(\mathrm{M})$, were determined by nonlinear regression analysis using PRISM (Graphpad Software Inc., San Diego, CA, USA). The $\log \left(1 / \mathrm{IC}_{50}\right)$ is the index of the binding activity and the mean values from two experimental runs were determined for each of 10 selected compounds.

\section{Hydrophobicity parameter}

$\log \mathrm{P}$, where $\mathrm{P}$ is the partition coefficient of compounds in the 1-octanol/water partitioning system, was determined by the shaking-flask method. ${ }^{23,24)}$ The concentration of compounds in the water phase was measured by HPLC using an ODS col- umn (LiChrosorb RP-18, Merck, Darmstadt, Germany) with a mixture of acetonitrile and water ( $3: 7$ to $1: 1$ by volume) as the mobile phase. For the correlation analyses, $\pi$ values, which are the differences of $\log \mathrm{P}$ for compounds with substituents from those without substituents, were used. ${ }^{24)}$ The $\pi$ values for test compounds are listed in Table 1 .

\section{Correlation analysis}

Variations in the neuroblocking activity were analyzed by using physicochemical parameters of substituents on the pyridine ring according to Eq. (1). ${ }^{25,26)}$

$$
\log (1 / \mathrm{BC})=\mathrm{a} E+\mathrm{b} \pi-\mathrm{c} \pi^{2}+\mathrm{d} \Delta S-\mathrm{e}(\Delta S)^{2}+\text { constant }
$$

The $E$ in Eq. (1) represents $F$ and/or $R$, which are the inductive and resonance components of the Hammett electronic constants, respectively. ${ }^{27}$ ) We chose these parameters, because substituted pyridines but not benzenes were examined in this study. The values were cited from literature. ${ }^{28)}$ The $\Delta S$ is the STERIMOL width parameter of substituents $\left(\Delta B_{5}\right)$ relative to the width of the hydrogen atom. ${ }^{29)}$ These physicochemical parameters are listed in Table 1. The a, b, c, d, e and constant are regression coefficients determined by the least squares method. To determine the existence of an optimum in the hydrophobicity and steric dimensions, the squared parameter terms were added so that $\mathrm{c}$ and $\mathrm{e} \geq 0$. Unless otherwise noted, statistical significance levels of the correlation equations and the independent terms in each equation were above $95 \%$ as examined by the $t$-test.

\section{Results}

\section{Neuroblocking and binding activities}

Before treatment of the central nerve cord of the cockroach with compounds, the nerve preparation produced small spontaneous discharges. Most of the test compounds immediately enlarged the impulses and increased the frequency, followed by subsidence to a level lower than the control when their concentrations were high enough. Figure 2 exemplifies the time courses for compound $\mathbf{6}$, in which each symbol indicates cumulative counts for every $30 \mathrm{sec}$ in each nerve preparation.

To evaluate the neuroblocking activity, the time when the firing number first decreased to a level lower than 10 counts per $30 \mathrm{sec}$, which was defined as $t$ in min, was determined (Fig. 2). The effects of the compound on the frequency and the time for subsidence depended on its concentration. Similar measurements were conducted at two concentrations for each compound as reported previously. ${ }^{17-19)}$ For each concentration of each compound, more than three nerve preparations were used. From the concentration-response relationship of each compound, the concentration required to reach one in terms of $\log t$ (that is, $t=10 \mathrm{~min}$ ) was determined (data not shown) and was defined as BC (in M) as reported. ${ }^{17-19)}$ The $\log (1 / \mathrm{BC})$ value was the neuroblocking activity and the values are listed in Table 1 with their deviation ranges. As shown in the table, the deviation was reasonably small. Among the 


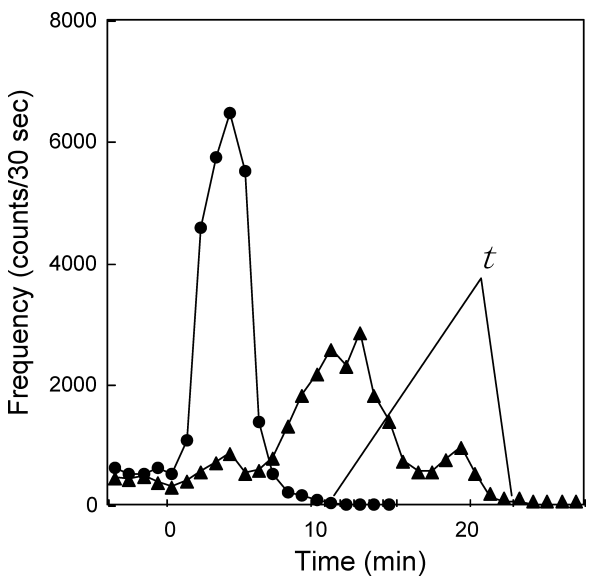

Fig. 2. Time courses of the effect of compound $\mathbf{6}$ on spontaneous discharges in the excised central nerve cords of Periplaneta americana. After counting the cumulative number of discharges every 30 sec for $5 \mathrm{~min}$, the saline was exchanged for saline containing the compound at $2.5 \times 10^{-5} \mathrm{M}(\boldsymbol{O})$ or $9.8 \times 10^{-6} \mathrm{M}(\mathbf{\Delta})$. The time of saline exchange was defined as the zero time.

tested chemicals, compound $\mathbf{2}$ with substituent $\mathrm{F}$ was the most active and slightly more active than compound $\mathbf{1}$ (imidacloprid). Compounds with other halogen atoms $(\mathbf{3}, \mathbf{4})$ had almost the same level of activity as compound 1. Compounds 11, 15 and 20 were weakest, but still had definitive values.

The binding activity in the housefly-head membrane preparation by using $\left[{ }^{3} \mathrm{H}\right] \mathrm{IMI}$ as a radioligand was measured for some selected compounds. As shown in Fig. 3, the binding activity of compound $\mathbf{2}$ was as potent as imidacloprid (1). Compound 16 was weakest and the activity value was smaller by $2.5 \mathrm{log}$ units than compound $\mathbf{1}$. The values of seven other compounds did not vary much and were within a unity in the $\log$ unit.

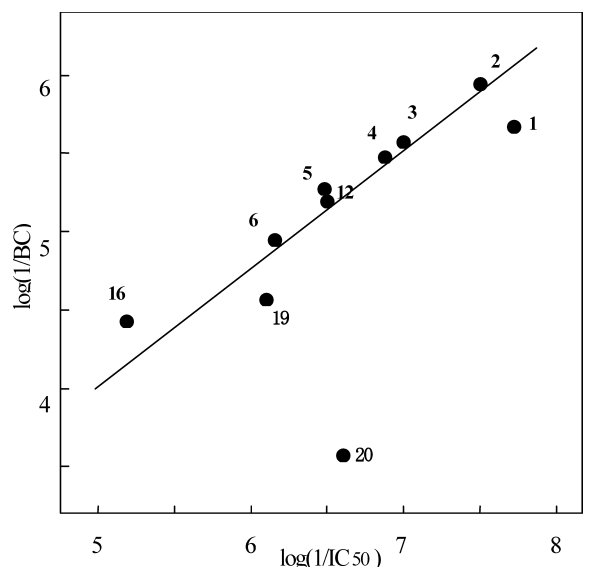

Fig. 3. Relationship between determined $\log (1 / \mathrm{BC})$ and $\log \left(1 / \mathrm{IC}_{50}\right)$ values among the tested compounds. A line was drawn for 9 compounds except for compound 20. The deviation ranges for the $\log \left(1 / \mathrm{IC}_{50}\right)$ values were up to \pm 0.21 (Table 2) and those for the $\log (1 / \mathrm{BC})$ values are shown in Table 1 .
2. Quantitative analysis of the substituent effects on the neuroblocking activity

Variations in the neuroblocking potency were quantitatively analyzed using Eq. (1) to give Eq. (2) as the best one.

$$
\begin{aligned}
\log (1 / \mathrm{BC})= & 5.480( \pm 0.306)-0.566( \pm 0.154) \Delta B_{5}-1.637( \pm 0.699) R \\
& n=21, s=0.342, r=0.877, F_{2,18}=29.93 .
\end{aligned}
$$

In Eq. (2) and the following equations, $n$ is the number of compounds, $s$ is the standard deviation, $r$ is the correlation coefficient, and $F$ is the value of the ratio between regression and residual variances. The figures in parentheses following the intercept and the regression coefficients are their 95\% confidence intervals. Since the activity values for most alkoxy derivatives were smaller than those calculated by Eq. (2) (data not shown), this equation was improved to give Eq. (3) by using an indicator variable, $I_{\mathrm{OR}}$.

$$
\begin{aligned}
\log (1 / \mathrm{BC})= & 5.365( \pm 0.283)-0.510( \pm 0.142) \Delta B_{5} \\
& -2.413( \pm 0.878) R-0.679( \pm 0.553) I_{\mathrm{OR}} \\
& n=21, s=0.298, r=0.913, F_{3,17}=28.55 .
\end{aligned}
$$

In Eq. (3), $I_{\mathrm{OR}}$ was set at unity for compounds 6-11 with alkoxy groups, but was set at zero for other compounds. Addition of the $F$ term or its substitution for the $R$ term did not improve Eq. (3). Equation (3) shows that the smaller the maximum width of substituents to the perpendicular direction from the pyridine ring-substituent bond, the higher was the nerve activity. The greater the electron-releasing resonance effect in terms of $R$, the higher the activity. The coefficient of the $I_{\mathrm{OR}}$ term means that the potency of compounds with the alkoxy groups is about $1 / 5\left(\log ^{-1} 0.679\right)$ lower than that of compounds without such substituents when their steric and electronic properties are equivalent. The oxygen atom at this position might interact with a hydrogen-bond donating acidic site, which is located opposite the effective interaction site, to reduce the activity. Table 3 shows the development of Eq. (3). Table 4 shows the correlation of variables used to derive Eq. (3). The $\log (1 / \mathrm{BC})$ values calculated by Eq. (3) are listed in Table 1.

Table 3. Development of QSAR of Eq. (3)

\begin{tabular}{crrrrrr}
\hline Intercept & $\Delta B_{5}$ & $R$ & $I_{\mathrm{OR}}$ & $s$ & $r$ & $F(X, Y)^{a)}$ \\
\hline 5.467 & -0.362 & & & 0.510 & 0.677 & 16.04 \\
5.480 & -0.566 & -1.637 & & 0.342 & 0.877 & 29.93 \\
5.365 & -0.510 & -2.413 & -0.679 & 0.298 & 0.913 & 28.55 \\
\hline
\end{tabular}

a) $F$ static for the significance of the addition of variables. $X$ : The number of independent variables added at each step of development. $Y: n-m-1, n$ being the number of datum points and $m$ being the total number of independent variables in the developed equation. Theoretical $F$ values: $F(1,19,0.05)=4.38 ; F(1$, $18,0.05)=4.41 ; F(1,17,0.05)=4.45$. 
Table 4. Squared correlation $\left(r^{2}\right)$ matrix for variables used to derive Eq. (3)

\begin{tabular}{lcccc}
\hline & $\pi$ & $\Delta B_{5}$ & $R$ & $F$ \\
\hline$\Delta B_{5}$ & 0.044 & & & \\
$R$ & 0.029 & 0.319 & & \\
$F$ & 0.219 & 0.027 & 0.001 & \\
$I_{\mathrm{OR}}$ & 0.018 & 0.376 & 0.664 & 0.000 \\
\hline
\end{tabular}

\section{Discussion}

Neonicotinoids act as agonists at the nicotinic acetylcholine receptor (nAChR) ${ }^{30,31)}$ Since the sixth abdominal ganglion of the American cockroach contains $\mathrm{nAChR},{ }^{32)}$ we chose this preparation for the electrophysiological experiments. As reported previously for various neonicotinoids, ${ }^{17,19,21)}$ compound 6 (Fig. 2) and all other compounds (data not shown) also showed a biphasic phenomenon consisting of increasing and decreasing phases in the frequency of spontaneous firing during treatment. We have found that neuroblocking activity in terms of $\log (1 / \mathrm{BC})$ is a more reliable neurophysiological parameter than the nerve excitatory activity, which was evaluated from the increasing phase during the treatment, ${ }^{17,19,33)}$ to correlate with the insecticidal activity. ${ }^{17,19)}$ We therefore only determined the blocking activity in this study.

The agonistic action of neonicotinoids can also be biochemically evaluated by the established binding assay method using a radioligand with the nerve homogenate preparation. We measured the inhibitory activity in the binding of selected compounds in the assay using $\left[{ }^{3} \mathrm{H}\right] \mathrm{IMI}$ as the radioligand. Figure 3 shows the relationship between the neuroblocking activity $(\log 1 / \mathrm{BC})$ and the binding activity $\left(\log 1 / \mathrm{IC}_{50}\right)$. Except for compound 20, all of the compounds showed a very good linear relationship $(n=9, s=0.288, r=0.937)$. The higher the binding activity to the housefly-head membrane preparation, the higher the blocking activity in the cockroach nerve preparation. Even though there is a difference in the insect species used for these tests, we can safely say that the binding of the compounds to $\mathrm{nAChR}$ initiates the blocking phenomenon. The blocking activity of the $\mathrm{NO}_{2}$ compound (20) was not as high as expected from the binding activity. One of the plausible reasons for the exceptionally low blocking effect of compound $\mathbf{2 0}$ may be in the $\mathrm{NO}_{2}$ group itself. It has been noted that neonicotinoid molecules interact simultaneously with $\mathrm{nAChR}$ at two sites at a certain distance; hydrogen bonding between the nitroimine oxygen atom and a hydrogen donator on the receptor site, and a Coulombic attraction between the electron-deficient nitroguanidinyl part and a $\pi$-donator on the receptor. ${ }^{34-36)}$ In this context, similar hydrogen bonding possibly occurs also toward the $\mathrm{NO}_{2}$ group on the pyridine ring of compound 20. However, the interaction of the $\mathrm{NO}_{2}$ group on the pyridine ring with the receptor will not give full nerve blockage as observed for the nitroimine moiety group, because of the inadequate positional relation to another interaction site. The same consequence can be applied for the $\mathrm{H}$-bond acceptor such as $\mathrm{CO}_{2} \mathrm{Me}$ and $\mathrm{CN}$ groups. ${ }^{37}$ )

Equation (3) shows that the introduction of substituents is sterically unfavorable to the blocking activity. A large substituent in terms of $\Delta B_{5}$ may be distorted by the $\mathrm{Cl}$ atom at position 6 to turn in an unfavorable direction for interaction with the target site. As an electronic effect, the negative sign of the $R$ term indicates that the electron-releasing resonance effect of the substituents on the pyridine ring is favorable to this activity. The higher electron density on positions 6 and/or 2 of the pyridine ring seems to enhance the interaction of compounds with receptors. The $I_{\mathrm{OR}}$ term might be involved in Eq. (3) to partially cancel out the effect of the $R$ term because of the rather high collinearity of $I_{\mathrm{OR}}$ and $R$ values (Table 4).

Azido compound $\mathbf{2 1}$ was found legitimately on the QSAR line regarding neuroblocking potency, even though its potency was obviously lower than that of imidacloprid. These present results may be contrasted with the binding tests on Aphid and Drosophila nAChRs, where the binding potency is almost comparable with that of imidacloprid. ${ }^{14,15)}$ The structural diversity and functionality of the insect nAChR have not fully been understood. ${ }^{38,39)}$ The subtle difference in receptor architecture among insect species and biological test methods may discriminate the behavior toward such an extremely reduction-sensitive azido molecule.

In summary, the introduction of substituents including halogens, alkoxy groups, alkyls and others into the 5-position of the pyridine ring of imidacloprid generally reduced neuroblocking activity. The reducing effect on blocking activity was well explained by the use of steric and electronic parameters. The introduction of alkoxy groups at this position was additionally unfavorable for activity. The neonicotinoids tested in this study probably bind first with nAChR, then cause blockage of the nervous system and kill the insects. A sequential scheme of this intoxication will be helpful to understand the mode of action of neonicotinoid insecticides, and the QSAR results will offer a clue to vary the combination of 5th and 6th substituents on the pyridine ring or design other substituted heteroaromatic rings for new potential insecticides.

\section{Acknowledgments}

We thank Earth Chemical Co., Ltd. for a donation of American cockroaches. This work was partly supported by the Grant-in Aid for Scientific Research to SK (No. 17580094) from the Japan Society for the Promotion of Science.

\section{References}

1) S. Kagabu: Rev. Toxicol. 1, 75-129 (1997).

2) R. M. Hollingworth: "Agrochemical Discovery: Insect, Weed, and Fungal Control," ed. by D. R. Baker and N. K. Umetsu, ACS Symposium Sries 774, Washington DC, pp. 238-255, 
2001.

3) K. Kodaka, K. Kinoshita, T. Wakita, E. Yamada, N. Kawahara and N. Yasui: "The 1998 Brighton Conference-Pests \& Diseases," 2A-1, 21-26 (1998).

4) T. Wakita, K. Kinoshita, N. Yasui, E. Yamada, N. Kawahara and K. Kodaka: J. Pestic. Sci. 29, 348-355 (2004).

5) T. Wakita, K. Kinoshita, K. Kodaka, N. Yasui, A. Naoi and S. Banba: J. Pestic. Sci. 29, 356-363 (2004).

6) A. Nakayama and M. Sukekawa: Pestic. Sci. 52, 104-110 (1998).

7) A. Okazawa, M. Akamatsu, A. Ohoka, H. Nishiwaki, W.-J. Cho, Y. Nakagawa, K. Nishimura and T. Ueno: Pestic. Sci. 54, 134-144 (1998).

8) A. Okazawa, M. Akamatsu, H. Nishiwaki, Y. Nakagawa, H. Miyagawa, K. Nishimura and T. Ueno: Pest Manag. Sci. 56, 509-515 (2000).

9) H. Nishiwaki, Y. Nakagawa, T. Ueno, S. Kagabu and K. Nishimura: Pest Manag. Sci. 57, 810-814 (2001).

10) S. Kagabu, H. Nishiwaki, K. Sato, M. Hibi, N. Yamaoka and Y. Nakagawa: Pest Manag. Sci. 58, 483-490 (2002).

11) H. Nishiwaki, Y. Nakagawa, D. Y. Takeda, A. Okazawa, M. Akamatsu, H. Miyagawa, T. Ueno and K. Nishimura: Pest Manag. Sci. 56, 875-881 (2000).

12) S. Kagabu, N. Ito, R. Imai, Y. Hieta and K. Nishimura: J. Pestic. Sci. 30, 409-413 (2005).

13) S. Kagabu, Y. Fujii and K. Nishimura: J. Pestic. Sci. 31, $150-155$ (2006).

14) S. Kagabu, P. Maienfisch, A. Zhang, J. Granda-Minones, J. Haettenschweiler, H. Kayser, T. Maetzke and J. E. Casida: J. Med. Chem. 43, 5003-5009 (2000).

15) N. Zhang, M. Tomizawa and J. E. Casida: J. Med. Chem. 45, 2832-2840 (2002).

16) S. Kagabu: Synth. Commun. 36, 1235-1245 (2006)

17) K. Kiriyama, K. Iwaya, S. Kagabu and K. Nishimura: J. Pestic. Sci. 26, 55-59 (2001).

18) S. Kagabu, A. Azuma and K. Nishimura: J. Pestic. Sci. 27, 267-271 (2002).

19) K. Kiriyama and K. Nishimura: Pest Manag. Sci. 58, 669-676 (2002).

20) M.-Y. Liu and J. E. Casida: Pestic. Biochem. Physiol. 46, 40-46 (1993).
21) S. Kagabu, K. Iwaya, H. Konishi, A. Sakai, Y. Itazu, K. Kiriyama and K. Nishimura: J. Pestic. Sci. 27, 249-256 (2002).

22) K. Kiriyama, H. Nishiwaki, Y. Nakagawa and K. Nishimura: Pest Manag. Sci. 59, 1093-1100 (2003).

23) OECD Guideline for Testing of Chemicals: No. 107, 1981

24) T. Fujita, J. Iwasa and C. Hansch: J. Am. Chem. Soc. 86, 5175-5180 (1964).

25) S. Nakagawa, N. Okajima, K. Nishimura, T. Fujita and $M$. Nakajima: Pestic. Biochem. Physiol. 17, 259-270 (1982).

26) C. Hansch and T. Fujita: J. Am. Chem. Soc. 86, 1616-1626 (1964).

27) C. Hansch, A. Leo and R. W. Taft: Chem. Rev. 91, 165-195 (1991).

28) C. Hansch, A. Leo and D. Hoekman: "Exploring QSAR-Hydrophobic, Electronic and Steric Constants," American Chemical Society, Washington DC, 1995.

29) A. Verloop, W. Hoogenstraaten and J. Tipker: "Drug Design," Vol. VII, Chapter 4, ed. by E. J. Ariens, Academic Press, New York, pp. 165-207, 1976.

30) D. Bai, S. C. R. Lummis, W. Leicht, H. Breer and D. B. Sattelle: Pestic. Sci. 33, 197-204 (1991).

31) M. Tomizawa and I. Yamamoto: J. Pestic. Sci. 17, 231-236 (1992).

32) M. E. Schroeder and R. F. Flattum: Pestic. Biochem. Physiol. 22, 148-160 (1984).

33) K. Nishimura, Y. Kanda, A. Okazawa and T. Ueno: Pestic. Biochem. Physiol. 50, 51-59 (1994).

34) S. Kagabu and H. Matsuno: J. Agric. Food Chem. 45, 276-281 (1997).

35) K. Matsuda, S. D. Buckingham, D. Kleier, J. J. Rauh, M. Grauso and D. B. Sattelle: Trends Pharmacol. Sci. 22, 573-580 (2001).

36) M. Tomizawa, N. Zhang, A. Durkin, M. M. Olstead and J. E. Casida: Biochemistry 42, 7819-7827 (2003).

37) R. W. Taft, D. Gurka, L. Joris, P. von R. Schleyer and J. W. Rakshys: J. Am. Chem. Soc. 91, 4801-4808 (1969).

38) E. D. Gundelfinger and R. Schulz: "Handbook of Experimental Pharmacology," Vol. 144, ed. by F. Clementi, D. Fornasari and C. Gotti, Springer, Berlin, Germany, pp. 497-521, 2000.

39) M. Tomizawa and J. E. Casida: Pest Manag. Sci. 57, 914-922 (2001). 